\title{
Pragmatics and the Internet in University Teaching
}

\author{
James Moody \\ Sultan Qaboos University, Oman
}

\section{The Internet and language in education}

Recent research shows that $71 \%$ of undergraduates in Oman use the Internet as a source of reading materials (Amer, 2004), a figure that will hardly surprise most teachers in higher education in the Gulf. In addition to acknowledging the irreversibility of this trend, many would probably applaud it as a positive development. The potential of the Internet in language development and other areas of learning has become a cliché. Kenworthy (2004), for example, stresses that through its use, learners are empowered in new ways: by engaging with real language in meaningful contexts, they become active creators instead of passive recipients of ideas. Similarly, El Hindi (1998) and Chafe (1999) propose that the Internet has revolutionized learning by providing opportunities for students to communicate realistically across a wide variety of domains. Chafe echoes a view of many educationalists: "The possibilities [of using the Internet in the classroom] are endless" (Benefits of Using the Internet/Section A, para. 3).

On the other hand, a number of disadvantages of the Internet in teaching have been noted. Although Stapleton (2005), for example, in reporting findings of a research project in Japan, recognizes that the Internet encourages a unique approach to the academic writing process, he also identifies some familiar problems. One of these is the use of inappropriate sources due to the difficulty of judging the value of texts when there is no control over what goes online. Another problem is that the quantity of material available facilitates plagiarism. Other questions about the role of the media generally in learning are raised by Haynes (2004), who calls for a critical approach that involves decoding texts through "discerning [their] methods and effects" ("Critical" Media Literacy section, para. 3). A possible misuse of the Internet results from its being ubiquitous and taken for granted: users of English as a Second Language (ESL) in particular may read linguistic signs at a superficial, literal level and fail to perceive the necessity for interpretation or evaluation.

One example of this danger is the uncritical assumption that when nothing is explicitly stated to the contrary, information is universally applicable; hence, student writers may use statistics indiscriminately when the original writer of an Internet text has, in assuming a shared context with a reader, not referred directly to the area to which these figures pertain. Another, more complex, problem is the tendency of Internet users to accept writers' opinions as facts. "Many of our students," Haynes observes, "do not yet understand [that] the message that was intended by the sender is not always the message that the students interpret" ("Critical" Media Literacy section, para. 5). She concludes that teaching should help students to "understand how and in whose interests the media operate" (Conclusion section, para. 3) and thereby provide them with a "healthy skepticism" (Conclusion section, para. 4). In other words, students need to read with the realization that the Internet, like all media-and like all language in use-is mediated through the consciousness of senders and receivers (de Beaugrande and Dressler, 1980).

El Hindi (1998) and Chafe (1999) value the Internet as supporting an interactive constructivist teaching methodology, whereby "students construct knowledge based on their own understandings and meanings of what they are working with" (Chafe, General Effects of Computer Use in 
Classrooms/Section F, para. 1). However, unlike Haynes, who is concerned with students learning English as a Foreign Language (EFL) in Japan, both El Hindi and Chafe are writing from the perspective of English as a Second Language (ESL) or English as a first language (EL1). In these environments, students are likely to be integratively or internally motivated, processing what they find on the Internet as aspiring members of communities comprised mostly of native English speakers, and in which English is the main language. This distinction between EFL and ESL is crucial, and a failure to observe it leads to pedagogical confusion. For example, Singhal (1997) takes for granted the aim of integration into an English speech community when she stresses the importance of Internet texts in giving EFL students a chance to experience the language in a cultural context. For her this means the first-language context in which the message is sent and in which the writer assumes it will be received; she neglects the possibility that the reader's community (mainly non-native speakers) may be different from that of the writer (mainly native speakers). For students in the Arab Gulf this is very often the case.

In considering the current literature on the use of the Internet in higher education, care should be taken to maintain the distinction between EFL and ESL: advantages claimed for one category of Englishlanguage users may not hold for the other. La Cava (2002), for instance, reports with approval the results of a study showing that $94.6 \%$ of adult ESL learners in the USA experienced a "perspective transformation" as a result of Internet use. Now this may be desirable when motivation is integrative (aiming for membership in another community), as students are likely to be learning ESL in order to communicate in a group of native English speakers. In the EFL contexts of the Gulf, however, although it is considered advantageous for students to open themselves to new experiences and broaden their general knowledge, whether education should set out to "transform" their "perspective" is more contentious. Although university students study partly in order to use the language receptively and productively within international academic discourse communities, there is also an increasing need to communicate in English locally, as the uses of the language for both professional and academic purposes are expanding throughout the region.

In spite of increasing competition from other languages worldwide, English remains the most common Internet language (Graddol, 2006). This fact has both obvious and subtle implications for EFL students in the Gulf. From the point of view of Western educators, it might seem that the dominance of English on the Internet can only be beneficial. On the other hand, a concern has recently been expressed by the manager of Google in the Middle East that less than one percent of global online content is available in Arabic "although Arabs make up five per cent of the world's population" (as reported in Moussly, 2010, p.8). On these grounds, she questions the much-vaunted ability of the Internet in the Arab world to foster a global village: "If you think of information as choice, as freedom, as power, or as an ability to reduce the digital divide between us versus them-less than one percent doesn't do much for us" (p. 8). But it is not only the language that makes these texts foreign in the Middle East and other EFL communities. As is apparent to any Internet surfer, most texts in English are not addressed to EFL users. Of equal concern to the Google manager, then-although this is not mentioned-should be the fact that a significant proportion of what is online is written in English by and for first-language speakers.

Much of the perceived pedagogical value of using the Internet seems based on the assumption not only that students seek to integrate into the culture which is reflected and embodied in the English language and in the Internet itself, but also that they read mainly for factual information. Language though can never be merely a means of information transfer because it is always encoded by a sender and decoded by a receiver. Advocates of the Internet in education (for example, Al Hindi, 1998; Chafe, 1999; Stapleton, 2005) often point to the opportunities it offers learners to experience English as used by native speakers, and thereby to expand their knowledge. This potential can hardly be denied. However, 
to conceive of Internet use in this way begs the question of whether students are or should be learning English to communicate as readers and writers within the context assumed by most Internet texts. If teaching in the Gulf is based implicitly or explicitly on such assumptions, it will fail to recognize the true instrumental motivation of students to use English in local multilingual contexts (see Moody, 2009a).

Kenworthy (2004) makes the point that using the Internet is compatible with the theoretical goals of the communicative approach to teaching writing. This too may appear self-evidently true, given the Internet's easy accessibility and interactive nature. However, the following discussion will attempt to refute this view by showing that the way some EFL university students in Oman approach the Internet in academic work indicates a failure to engage in real communication, and that consequently their use of it as a source for research and writing is incompatible with the pragmatic principles underpinning communicative language teaching. In order to make this case, relevant theories about the relationship between readers and writers and their implications for learning and teaching will first be considered. Then specific examples of work students have produced will be discussed. Finally, a recommendation will be made for how teachers might deal with the problem by encouraging students to become more critical as both readers and writers of English.

\section{Pragmatic theory in reading and writing}

Basic to pragmatics (the study of language meaning in context) is the interdependence of sender and receiver. The prototype for all communication is taken to be conversation (Levinson, 1983), in which meaning is not so much asserted or retrieved as negotiated; the same principle holds for reading and writing. Stubbs (1996) claims that meaning depends on three elements: the language of a text, who produced it, and who responds to it; but it is the dynamic interaction among all these factors that creates meaning. Mey (2001) has used the term "addressivity," by which he means that any spoken utterance or written text is always addressed to someone and is therefore "dialogic" (p. 271). This implies that readers are required to react to a text, which in turn means that they must possess the necessary mental equipment to do so. de Beaugrande and Dressler (1980) present a typology of preexisting "global patterns" stored in a reader's mind: frames, "commonsense knowledge" about central concepts; schemas, progressive patterns of events in ordered sequence; plans leading to intended goals; and scripts specifying roles of participants in established routines (p. 90).

When confronted with texts, successful readers activate these patterns and use them to create hypotheses and make predictions. Their suppositions may turn out to be mistaken, and when that happens they need to be revised. Often the most interesting writers are those who flout readers' expectations; many (perhaps most) literary works intentionally manipulate readers in this way. But it is through the reader's ongoing testing of segments of a text against stored mental concepts, and if necessary, renegotiating their relationship with what they have read, that meaning is produced. This general communicative and epistemological principle applies not only to reading but also to education generally: we comprehend new information by relating it to what we already know. Thus, the focus of a reading methodology should be on what is happening in a reader's mind-how mental structures are activated and how hypotheses are tested and revised during the process of reading-rather than on assessing the product of this process, as tends to happen in traditional comprehension exercises (Moody, 2009b).

Gutierrez (1995) applies these insights to academic reading and writing. She argues that students should first acquire sociocultural knowledge about what it means to be a member of an academic community. The resulting "interactional competence" is part of a "social contract" (p. 23) and as such is just as 
essential as competence in grammar or spelling. Gutierrez concludes that the appropriation of academic discourse requires an internalization of tools for reading. For this reason, she advises against low-level or remedial teaching on the grounds that it does not provide such insight into social reality, upon which the construction and application of global mental patterns depend. These concepts suggest two possible problems for EFL students in the Gulf when reading texts in English. One is that they may lack the necessary patterns. This is not only a matter of having inadequate information about the world, as teachers sometimes complain, but it also has to do with making connections among disparate aspects of experience and then generalizing from them. Another problem is that students who do possess these mental structures may not apply or activate them appropriately as EFL readers.

These pedagogical challenges can be considered in terms of the distinction made in pragmatic theory between text (what is written on the page) and discourse (how what is written becomes meaningful). Widdowson (2004) is concerned with the way in which readers derive discourse from text through interpretation. Any text (from a literary work to an engineering report or a blog) has within it varying possible meanings, and the interpretation that is "realized" depends on what Widdowson terms readers' "pretext" (p. 79), basically their purpose in reading. Widdowson is equally concerned with the reverse process: how writers too construct texts according to their own pretexts. He sums up the relationship succinctly: "It is your discourse that you read into my text" (p. 13). The text, then, is permanent, but its meaning is variable. Therefore, the context in which language is sent and received becomes less a matter of particular features of external reality (as this term has often been interpreted) than of assumptions being made about the world, or participants' psychological constructs (Sperber and Wilson, 1995). This formulation has similarities with and includes de Beaugrande and Dressler's (1980) notion of global patterns. What is relevant in the context and the pretext, and therefore in the construction of meaning, is what both communicative participants choose to make relevant.

Thus, a problem arises when there is a significant disparity between what sender and receiver take to be relevant, that is, when there is little or no correspondence between assumed and actual readers. In one sense, it is always the case that receiver's purpose and sender's intention can never be identical; every act of reading always becomes a translation (Steiner, 1975). Although social life would be impossible without a degree of overlap between intended and received meanings, it is not unusual for writers to be surprised at new meanings discovered by readers of their texts. However, Widdowson (2004) claims that to the extent writers and readers belong to the same discourse community and share the same sociocultural values and conventions of use, "the writer's purpose will be recognized and ratified in the interpretation of readers for whom it is intended" (p. 86). He is not directly concerned with what can happen when sender and receiver belong to different communities, but he recommends that future research be conducted into how groups of readers of varying socio-cultural-political backgrounds respond to various kinds of texts.

The possible discrepancy between what a sender intends and what a receiver interprets has important implications for EFL students' use of Internet sources in writing assignments. Since they are placed in a position in which the texts they read are unlikely to be intended for them, their global patterns and pretexts may not correspond to those of the writers whose texts they read. These mental constructs may also be unclear and confusing to inexperienced readers. It is perhaps ironic that much of the praise of the Internet as promoting social interaction has neglected the pragmatic dimension of its actual use by EFL students. El Hindi (1998), for instance, in stressing how the Internet can promote the social construction of meaning fails to address the question of who is interacting with whom, what assumptions are made by writers about readers, the writer's and reader's particular (and perhaps different) purposes, and how all these might affect the nature of the meaning constructed through 
interaction. Such factors become problematic when EFL students are reading and using texts produced by and for native English speakers. Some specific problems for these students in Oman will now be examined.

\section{Pragmatic issues for students of academic writing}

Academic Writing is a third year (semester five) 15-week course in a four-year degree program for education students in the English Department at Sultan Qaboos University. Students in this course base their writing (including a major term paper) on reading they have done (often from the Internet) about a topic related to Oman and chosen by themselves. Hence, this is as much a course in critical reading as in academic writing. Students are expected to comprehend, assess, respond to, and use written sources in an argumentative essay which develops their thesis. Of course, there are many stances they can take with regard to these sources. They may accept what the texts say and extend or apply this to Omani data; they may reject the ideas and give reasons for doing so; and there are many positions in between. But what they should not do is simply assume that a text is reporting unmediated facts. In addition to relating the material to their own purpose in writing, they should be able to detect the purpose of the writer who produced it. Through this process, it is hoped, they will come to realize that even if a given text does not exhibit academic features itself, there can be academic discourse in their written response to it.

To achieve these aims, two purposes of reading for writing are stressed. First is the need to read generally about a topic: to discover ideas that will lead to a thesis to be argued in the final essay. Any kind of reading is suitable for this purpose, even popular websites like Wikipedia and About.com, for example. However, once a topic is finalized and a thesis statement formulated, then the search should focus exclusively on academic texts, which will be the sources cited in the final essay. Class time is spent on explaining how to identify academic sources by external features (nature of the website, date, author, publisher/sponsor) and internal considerations (organization, logical argument, evidence, use of citations of other texts). The criterion for selecting the sources to include is the projected plan of the essay: texts need to be chosen on the basis of their suitability and effectiveness in arguing the thesis of the final paper. However, partly because of the proliferation of unfiltered information on the Internet and the resulting difficulties in judging the relative value and authority of texts, the process of making a thoughtful selection is often so taxing that when students do choose a source text, they may read it literally instead of pragmatically.

The supposition that language in use is a transparent means of conveying information objectively, without mediation of a sender or receiver, can result in students' reluctance to engage in argument or controversy or to perceive it in others. On a test in an Academic Writing class during the second semester 2009-10, for example, a text was given concerning coeducation at universities in Oman, and students were asked to respond to it in an academic essay. This text (Eyes Wide Oman, 2008) was written on the Internet by an anonymous expatriate tertiary teacher in Oman. It presents her view that university students (especially females) are subverting the official policy of co-education by having nothing to do with the opposite sex even when they are present in the same classroom. Students might have appropriately reacted to this text in several ways, including:

(a) accepting the writer's point of view and then trying to explain why it is the case that women and men voluntarily segregate themselves; 
(b) agreeing with the writer that coeducation is a good idea but disagreeing with her opinion that it is not being implemented, possibly by giving counter-examples of how males and females do collaborate;

(c) opposing the idea of tertiary coeducation in Oman altogether, giving reasons for doing so, and accepting that in taking this position they are disagreeing with official policy.

What was not expected was what some students did: ignore the text entirely. Many essays extolled the advantages of coeducation as a general ideal, while neglecting evidence of its incomplete implementation which was given by the writer and which they could themselves verify through direct observation: that men and women while taking this test were sitting in the classroom as far apart as they could possibly be. This example illustrates a failure to connect a text to what the reader knows. In this case, even though the Internet text was about Oman and even about what they could physically see before them, some students refused to involve themselves in what it said. Although the text seems to have been addressed mainly to the writer's fellow expatriates, not to Omanis, a perception of the relationship assumed between sender and receiver might have encouraged students to take position (b) or (c) and to argue that the writer is unfamiliar with Omani society, is failing to consider some other relevant factors, and/or is judging from a foreign point of view.

Further evidence indicates that there are several ways indiscriminate-or, more precisely, unpragmatic-use of the Internet can negatively affect academic writing. These examples are taken from the work of a total of 25 students in two groups, one in the first and one in the second semester of the 2009-10 academic year.

Firstly, students may overlook the communicative nature of texts altogether and treat them as objective reporting. The result is an uncritical use of sources, without regard to their context or assumptions. Sometimes this can be at the level of word choice, as in the case of an essay on the Mona Lisa which said that the painting is an important part of our culture, using a pronoun taken verbatim from the source without regard to the writer's identity and how it differs from their own. Inappropriate or irrelevant information is sometimes included, as in an essay about the value of playing Omani traditional games in which competing in the Olympics was mentioned several times, or in this extract from an essay about Omani traditional medicine:

Pure and genuine herbs are available inside and outside the home. Kitchens and backyards have stocks of herbs like garlic, peppermint, onion, ginger and lemon. People may not consider how they have healthy effects on their bodies (Vanessa, 2008). Supermarkets have plants like grapes, guavas, oranges and papayas that cheep [sic] and beneficial too. For example, the leaves of guava tree are good disinfectants for open wounds (Shia, Show and Dagan, 2004). When people ground the leaves of guava and put them in open wounds, they may be disinfected. Also the guava is the best cure for tooth decay and gum problems (Shia, Show and Dagan, 2004).

Here, by simply reporting what the source texts say, the writer is implying inaccurately that most Omanis have these herbs in their kitchens and grow them in their gardens and that papayas and guavas are easily available in local supermarkets. A similar example comes from a discussion of the need for Omani students to develop self-study habits:

In addition, the freedom to study anywhere and anytime gives them the motivation to learn. They can go and study "in an environment where there is no pressure to stay with the materials (no teachers, classrooms, periods, or exams) such as public libraries, shopping centers" (Bork \& Gunnarsdottir, 2001, p.70), parks, and any other places they feel comfortable in. 
If this writer had given more consideration to the context of Muscat, the idea of studying in a shopping center might have seemed less appropriate.

Sometimes facts and statistics are used that relate to other places, but in the context of the essay they appear to be about Oman. Only the citation in the following example (from an essay on corporal punishment) indicates that the Department of Education and the numbers given relate to another country:

It has been argued that many in boys' secondary schools have already been punished by their parents or when they were in elementary schools. According to Robison (2005), a Department of Education report found that $73 \%$ of parents with children aged 3 to 17 used corporal punishment over a 12-month period and more recent studies have reported that over $90 \%$ of parents have been spanking their children. (http://www98.griffith.edu.au/dspace/handle/10072/4607)

A further problem is that student writers may limit themselves to reporting the information given in a source and refuse to expand it by applying what it says to the local situation. The following is from an essay by another student arguing against the use of corporal punishment in Omani schools:

Moreover, punishment differs from one culture to another. It also depends on the country which the person belongs to. In some cultures, punishment is necessary and a normal action to discipline children. They believe that punishment is associated with discipline. However, in other cultures corporal punishment is one form of child abuse.

This is a valid distinction between the ways two kinds of culture consider punishment, as far as it goes. It could be a point of departure for discussing attitudes to punishment in Oman and comparing them to those in other places, but the writer refuses to say which cultural type Oman belongs to, and prevents himself from pursuing the point.

Similar to both these examples is a failure to develop a discussion by applying data from elsewhere to Oman, as in the following discussion of suicide:

Moreover, we can consider poverty one of the economic problems which may lead a person to suicide, according to Evans and Farberow (1998) who say that "suicide occurred more frequently among the laboring poor in urban settings." In addition, poverty is a public problem that many people suffer from, especially in the poor countries, so poverty can be one of the factors that affect and shape the overall dynamics of suicide phenomenon.

Here the writer does not say whether the same is true of Oman or whether she considers it one of the "poor countries" (and if it is not, it is difficult to see how this information would be relevant to an essay about suicide in Oman).

By attempting to place themselves in the communicative position of the reader that the writer of an Internet text has assumed, students may abandon their own identity as Omani readers. If we read only for facts or information, it is easy to overlook pragmatic relationships embedded in a text. Sometimes using Internet sources appears to limit, rather than expand, students' horizons. They tend to take current issues discussed and debated online as having perfunctory significance for their own lives or at least as worthy of their discussion. For example, students have proposed the following topics for research essays about Oman:

- What are the advantages and disadvantages of online dating?

- Should gay couples be allowed to adopt children?

- Where does responsibility for the economic crisis in Africa lie?

- Should governments be responsible for citizens' health care?

Moody, J.A. (2011). Pragmatics and the Internet in university teaching. Learning and Teaching in Higher 
The fact that dating and gay couples are rare in Oman did not seem to affect these choices, nor was the relevance to Oman of the economics of Africa or debates about health care (in the USA) considered. Another student wanted to write on the history of women's fashion without planning to mention fashion in the Arab world.

In the Academic Writing course during the first semester 2009-10, students were given an assignment to write an argumentative essay on the question: Is the use of torture ever justified? As preparation, they studied two essays, one making a case for the use of torture in certain circumstances and the other supporting the idea that torture is always wrong. They were asked to find additional material, decide which side they supported, and defend one and critique the other. Several students used a satirical text they had found on the Internet titled "Good torture-Some torturers are born; the best are made" (Jamieson, 2009). The text contains the following introductory statements:

"I'm covering my bets and coming out in favor of torture. Bring it on, I say! The more, the merrier! Torture all around!" (para. 1);

"Damn, I feel manly when I talk that way. " (para. 2);

"I mean, look, it's not as if I'M the one getting tortured. The government promises to only torture people they don't like, and darn it, I'm a likeable guy. They won't come after me" (para. 3);

"... [I]f we are going to have torture, we have to make it as efficient as possible, and one of the main problems... is that of getting the right people for the job of torturing" (para. 4).

The writer goes on to consider a number of personality types that might make suitable torturers and their qualifications:

- Psychopaths who are "oblivious to the pain of others" (para. 8) would make "darned good torturers" (para 10);

- People with Sadistic Personality Disorder: no, because they will "go through victims at a pretty fast clip" (para. 13) and may tell lies to make their bosses suffer too;

- Fundamentalists: no, because they only want to punish evil, not to extract information;

- Narcissists: no, because they are too self absorbed and want power for themselves, not for their employer;

It is then explained how socially maladjusted individuals might be made into "happy and productive citizens" (para. 19) through becoming torturers, and detailed recommendations are made for how they could be trained to do this work. The conclusion is:

"America has always prided itself on its morals and resourcefulness, and we owe it to the world to have the best torturers we can find, people willing to torment without (too much) joy and able to extract answers, even when they know there are none to extract" (para. 25).

"Good torture is a delight in the eyes of God. Bad torture is just tacky" (para. 26).

In the essays they wrote, students using this text as a source interpreted it as supporting the use of torture. By considering it as transparent reporting, they failed to perceive its almost Swiftian irony and understood it to be literally about recruiting and training torturers. Detecting irony and satire is a complex decoding process. Here note needs to be taken of such features as logical inconsistencies, an informal style and a mock self righteousness adopted by the persona. Most of all, a reader needs to respond critically to the proposition that society should take advantage of the sadistic tendencies of social misfits and make productive use of them. These students failed to relate this text to their own experience, values, and mental patterns as receivers of the text. Even if an Omani reader interpreted the text as sincerely intended, a pragmatically involved reaction would still demand outrage that someone could hold these opinions. To believe that the text presents literally a legitimate perspective would be a 
misinterpretation, but at least a reader repelled by its ideas would be giving a reasoned reaction and could then go on to attack the insensitivity of a writer who could have such views.

To some extent, such problems exist for EFL readers of all texts that assume native English readers. But many Internet texts, unlike most books in university libraries, engage with readers in a personal, informal manner. Furthermore, since they are likely to be accessed along with more scholarly formal material (also available online), it can be difficult for students to distinguish the former from the latter. The tendency of students to leave unanalyzed pragmatic relations between sender and receiver asserted by Internet writers, can lead by default to cultural indoctrination. By suspending their own identity, they are trying to become the kinds of readers (usually middle class native speakers of American English) that most writers on the Internet assume. Because these assumptions remain unstated and only implied in the texts, the results for Omanis of reading in an unmediated way may be a more serious threat to maintaining their national or cultural identity than exposure to overt propaganda would be. In terms of the pragmatic paradigm of conversation, they are trying to cast themselves in the role of a participant rather than as what they really are: a member of an EFL speech community who "overhears" a communicative interaction between EL1 interlocutors.

\section{Conclusion: Towards a pragmatic pedagogy of reading and writing}

What these examples suggest is that when using the Internet Omani students need to position themselves pragmatically as critical eavesdroppers on communication between foreigners, given the fact that the majority of the texts in English on the Internet are written by and for native speakers of English. EFL instruction that makes use of the Internet should focus on developing students' ability to approach these texts as observers rather than as participants. This does not mean that their responses will be uninteresting or trivial, nor that reading should be pursued at a remedial level. In listening to conversations between people we do not know, we need to work imaginatively in order to make sense of what is overheard. Critical comprehension involves understanding unstated pretexts $-a$ fact that many modern dramatists have exploited in their plays. This way of approaching texts can be productive and valuable, for it can tell us something about the opinions and attitudes of people different from us, outside our speech community. For example, one reason why Omanis might be interested in reading English-language newspapers in Muscat, where there are also several Arabic papers, is not so much to know the news but to discover what expatriates think (and say to each other) about Oman.

It might be considered that the role of third-party eavesdropper is in some way pragmatically inferior to that of first- and second-party interlocutors, since it does not appear to involve active negotiation of meaning between sender and receiver. But the idea that an eavesdropper is in some way less important than a conversational partner involves a misunderstanding of the nature of communication. If meaning is achieved interactively, then third-party eavesdroppers would seem to be in a privileged position, because they can discern more clearly what occurs. They can observe analytically the processes through which meaning is created. As eavesdroppers they retain their own identity and filter what they hear or read through their own mental patterns, their background, experience, beliefs, and values-including their concepts of what is factual, logical, and reasonable. It is only through EFL readers' judgments as eavesdroppers on texts written by and for first-language speakers that pragmatic meaning emerges.

The Internet is rightly considered to be a tool of empowerment. But as with other powerful tools, care must be taken in its use; otherwise, it can have an opposite effect. Rather than "reducing the divide between us" (Moussly, 2010, p.8), it may result in alienation and the development of a false identity. This is an aspect of the larger issue of globalization, which, in the process of turning the world into a 
single village, can amount to making 'us' more like 'them'. The results for higher education in the Gulf are that students are not engaged in what they are doing because they are not using language to communicate in the pragmatic ways that have been considered here. It sometimes appears that what students experience through the medium of English is limited to what they read on the Internet. Many advocates of the Internet in education, as has been shown, stress its interactive nature. But too exclusive an engagement with the "virtual" Internet may prevent EFL students from interacting in their own real Omani and Arab Gulf speech communities, where English is being used for an increasing number of social and professional functions. In this way, the Internet may influence these students to neglect their own identity, both as thinking individuals and as citizens, when they are using English. Since the content of the Internet is uncontrolled and largely mediated by and for native English speakers, it is the responsibility of Omani and other Arab users to take control of and "localize" what they find there.

University teachers in the Gulf, especially of academic writing, have a role to play in this process. They need to consider these possible dangers, particularly in light of the pervasiveness of the Internet and the almost unanimous support it receives from educational practitioners. Students should be encouraged to think pragmatically and critically about any text they read, instead of concentrating on its literal content. Tasks can be designed so as to avoid some of the problems that have been considered here. One type of exercise, for example, could be to analyze how particular Internet texts might be used and misused in thesis development. Teachers could show students how to interact with and position themselves in relation to these sources. Students would develop the skill and imagination to assess whether they are the assumed reader of a text and, if not, how to adopt appropriate strategies to deal with this communicative situation. If they do not acquire these abilities, they will produce essays that take cognizance of neither the contexts in which sources are written nor their own pretexts and identity as Arab writers in English.

\section{References}

Amer, A.A. (2004). International report on literacy research, Sultanate of Oman. Reading Research Quarterly, 39(4), 480-481.

Chafe, A. (1999, November). Effective use of the Internet in second language education: Benefits, challenges, and guidelines for teachers. The Internet Classroom. Retrieved from http://www.cdi.ca/ achafe/Internetinclassroom.html

de Beaugrande, R. \& Dressler, W. (1980). Introduction to text linguistics. London: Longman.

El Hindi, A.E. (1998). Beyond classroom boundaries: Constructivist teaching with the Internet. The Reading Teacher 5(8), 694-699.

Eyes Wide Oman (2008). Co-education? we all know what happens when boys and girls study together... Retrieved from http://eyeswideoman.blogspot.com/2008/12/co-education-we-all-know-whathappens.html

Graddol, D. (2006). English next. London: British Council.

Gutierrez, K.D. (1995). Unpackaging academic discourse. Discourse processes, 19(1), 21-37.

Haynes, L. (2004, June). Creating discerning students: Media literacy in EFL. Academic Journal of the Nazan Academic Society, Literature and Language, Nazan University [Japan], 76. Retrieved from www.hum.nagoya-cu.ac.jp/ louise/research/index.html 
Jamieson, B.Z. (2009, May 10). Good torturers: Some torturers are born; the rest are made. We! Magazine. Retrieved from http://www.wemagazine.org/good-torture-some-torturers-are-born-thebest-are-made/

Kenworthy, R.C. (2004). Developing writing skills in a foreign language via the Internet. The Internet TESL Journal 10(4). Retrieved from http://iteslj.org/Techniques/Kenworth-WritingSkills.html

La Cava, D.S. (2002). Perspective transformation in adult ESL learners using internet technology. ETD Collection for Fordham University. Paper AA13056144. Retrieved from http://fordham.bepress.com/dissertations/AA13056144

Levinson, S.C. (1983). Pragmatics. Cambridge: Cambridge University Press.

Mey, J.L. (2001). Pragmatics: An introduction, $2^{\text {nd }}$ ed. Malden, MA: Blackwell.

Moody, J. (2009a). A neglected aspect of ELT in the Arabian Gulf: Who is communication between? In L.J. Zhang, R. Ruddy, and L. Alsagoff (Eds.), English and literature-in-English in a globalized world. Singapore: National Institute of Education, Nanyang Technological University, 86-106.

Moody, J. (2009b). Making sense: Reading as interactive communication. In T. Roach (Ed.), Orientations in language learning and translation. Muscat: Al Falaj Press, 61-70.

Moussly, R. (2010, March 1). Call for more online Arabic content. Gulf News.

Singhal, M. (1997). The Internet and foreign language education: Benefits and challenges. Internet TESL Journal 3(6). Retrieved from http://iteslj.org/Articles/Singhal-Internet.html

Sperber, D. \& Wilson, D. (1995). Relevance: Communication and cognition, $2^{\text {nd }}$ edn. Oxford: Blackwell.

Stapleton, P. (2005). Using the web as a research source: Implications for L2 academic writing. Modern Language Journal, 89(2), 177-189.

Steiner, G. (1975). After Babel: Aspects of language and translation. Oxford: Oxford University Press.

Stubbs, M.W. (1996). Text and corpus analysis: Computer assisted studies of language and culture. Oxford: Blackwell.

Widdowson, H.G. (2004). Text, context and pretext: Critical issues in discourse analysis. Oxford: Blackwell. 